\title{
LOS DETECTIVES SALVAJES Y EL CRIMEN DE LA ESCRITURA
}

\author{
Juan Campesino ${ }^{1}$ \\ Centro Nacional de Investigación, Documentación e información \\ Teatral Rodolfo Usigli, México
}

Resumen: Una vez identificados sus nexos intertextuales con algunos de los principales exponentes del relato de detectives, un aspecto poco o nada estudiado de la novela de Roberto Bolaño, el presente artículo atiende a la naturaleza paródica de los detectives salvajes $\mathrm{y}$, en especial, a la reflexión negativa sobre la escritura misma que toda parodia, y la de Bolaño no es la excepción, pone en marcha.

Palabras clave: Roberto Bolaño; relato de detectives; parodia; intertextualidad.

Recibido: 26 de marzo de 2019

Aprobado: 20 de agosto de 2019

\section{The savage detectives and the crime of writing}

Abstract: after identifying its intertextual ties with some of the most prominent detective stories, a hardly studied aspect of Roberto Bolaño's novel, this paper looks upon the savage detectives' parodic nature and specially upon the negative reflection about writing itself that runs on every parody, where Bolaño's is not the exception.

Keywords: Roberto Bolaño; detective stories; parody; intertextuality.

\footnotetext{
${ }^{1}$ Doctor en Letras por la Universidad Nacional Autónoma de México, maestro en Letras Latinoamericanas por la misma institución y licenciado en Literatura y Ciencias del Lenguaje por la Universidad del Claustro de Sor Juana (títulos que ha obtenido, en todos los casos, con honores). Correo electrónico: jcretes@yahoo.com.mx
} 
It seems to me that crimes are so often associated nowadays with the young. People who don't really know quite what they are doing, who want silly revenges, who have an instinct for destruction. Even the people who wreck telephone boxes, or who slash the tyres of cars, do all sorts of things just to hurt people, just because they hate - not anyone in particular, but the whole world. It's a sort of symptom of this age.

Rowena Drake

Las víctimas de la palabra se cuentan por millares.

Ramón López Velarde

\section{Los intertextos salvajes}

Desafortunadamente, la parodia es un tema que la crítica sobre Bolaño, y en particular sobre Los detectives salvajes, ha dejado de lado. Hasta donde sé, nadie ha reparado con atención en el tratamiento paródico del relato detectivesco que, en su novela más connotada, el chileno efectúa sobre la base de los pilares del género, lo que sin duda ocurre en la misma medida en que, por ejemplo, y guardada toda proporción, Cervantes lo hace con los libros de caballería y Flaubert con la novela sentimental. ${ }^{2}$ Ello, con el agregado de que, por tratarse justamente del género de detectives, la novela de Bolaño se presta como ninguna otra para comprender plenamente el concepto mismo de parodia y sus implicaciones en el marco no ya únicamente de la literatura, sino de la escritura en general. Me interesa aquí no tanto esclarecer los vínculos paródicos entre un texto y sus modelos, como subrayar la clase de función que desempeña un texto paródico en tanto que plataforma retórica para transmitir una tópica distinta y opuesta a la de sus modelos.

En términos generales, la teoría contemporánea ha atribuido a la parodia la tarea de contrastar las semejanzas formales entre unos textos y otros (Tinianov 101; Genette 54, Sangsue 54) y, en el mejor de los casos, la ha considerado una suerte de compañera retórica de la sátira (Hutcheon, "Ironie"; Nash 85), pero poco ha reparado en la función sustancial que, antes de poner sus miras en el mundo fuera del texto,

\footnotetext{
${ }^{2}$ Sugerencias de dicho tratamiento se hallan, a lo largo de toda la novela, en numerosos marcadores tanto gráficos como diegéticos. Al margen del título de la obra, baste mencionar la afición de Arturo Belano a las novelas policíacas y el caligrama de Cesárea Tinajero, a caballo entre el enigma y la broma.
} 
la parodia desempeña en el marco de las relaciones entre unos textos y otros. En este sentido, el concepto de intertextualidad acuñado por Kristeva no termina de hacer justicia a las filiaciones bajtinianas de la autora, cuya lógica poética pasa por alto que para Bajtín la parodia está llamada a "recrear el lenguaje parodiado como un todo esencial que posee su lógica interna y que revela el mundo especial ligado de modo inseparable al lenguaje parodiado" (Problemas 203). Claude Bouché constituye, en este mismo sentido, la excepción a la norma, a pesar de que su análisis de Lautréamont se concentra casi exclusivamente en las operaciones formales que el uruguayo efectúa sobre sus modelos.

A propósito de operaciones formales, ahí está el desdoblamiento ad nauseam de los narradores en la segunda parte de Los detectives salvajes, haciendo eco de la seguidilla de testimonios que, en "Los crímenes de la Calle Morgue", cuento con el que Poe inaugura el relato de detectives, le basta a Dupin para resolver el misterio y que, a la postre, se convertirá en un estándar del género (pienso en Agatha Christie, sobre todo en Asesinato en el Orient Express). Ahí también las inversiones, primero, del esquema temporal que Bolaño recupera de Estudio en escarlata y El valle del terror, primera y última novelas del canon holmesiano, ${ }^{3}$ segundo, del contexto genérico correspondiente a cada apartado, ya que la segunda parte de El valle del terror instaura lo que más tarde se conocerá como novela negra, género que, por el contrario, en Los detectives salvajes permea las partes primera y tercera, cuando que en la segunda predomina el estilo de la novela enigma o de cuarto

\footnotetext{
${ }^{3}$ Ambas se componen de dos partes desarrolladas en tiempos y con narradores distintos y seguidas de un epílogo. En los dos casos, Conan Doyle recurre a una extensa secuencia de acontecimientos pasados para esclarecer el móvil del crimen, pero a diferencia de lo que ocurre en Estudio en escarlata, donde por un lado se deja en suspenso la solución del enigma y por otro la secuencia de acontecimientos pasados se enlaza cronológicamente con el final de la investigación, en El valle del terror la narración de los antecedentes se ofrece una vez resuelto el misterio y, a su término, un breve epílogo cierra administrativamente el caso al tiempo que deja un cabo suelto, sugiriendo la posibilidad de una continuación. En la medida en que la elipse temporal suspende la solución del misterio, y el final de la historia queda abierto a una posible continuación, el de Bolaño se amiga y enemista con ambos relatos del británico, si bien la remisión intertextual se dirige sobre todo al más reciente de los dos.
} 
cerrado, ${ }^{4}$ y tercero, de las convenciones propias de cada subgénero. ${ }^{5}$ Y, más aún: el desplazamiento del crimen que, a diferencia de sus modelos, Bolaño hace figurar en las últimas páginas de su novela. Al margen del narrador testigo que acompaña al detective, presente junto a Dupin en el relato de Poe y junto a Sherlock Holmes en la narrativa de Conan Doyle, y que, como hace Eco en El nombre de la rosa, Bolaño replica sin variaciones sustanciales en la figura de Juan García Madero, en cada caso mencionado se aprecia la puesta al desnudo de un cliché estructural e, incluso, su radical destrucción (Lotman 354), toda vez que

\footnotetext{
${ }^{4}$ Para una comprensión cabal de las distinciones entre las tradiciones clásica y negra del género detectivesco, ver Chandler, Piglia y Giardinelli. En términos generales basta, para el caso, con comparar los respectivos métodos de Holmes, expuesto en su primera aventura: "Nos encontramos con el hilo rojo del asesinato enzarzado en la madeja incolora de la vida, y nuestro deber consiste en desenmarañarlo, aislarlo y poner a la vista hasta la última pulgada", y el del Sam Spade de $E l$ halcón maltés, de Hammett, consistente en "arrojar, violenta e impredeciblemente, una barra de hierro en medio de la maquinaría". En este sentido, El valle del terror resulta la más completa de todas las obras del género, ya que reúne en un único cuerpo la novela enigma o de cuarto cerrado, cuyas filas engruesan los miembros del Detection Club londinense, y el thriller detectivesco, enfocado no tanto en el misterio y su solución como en la personalidad del detective, y cuyo origen, si británico — la novela de Conan Doyle es anterior a Hammett y sus contemporáneos—, se liga al contexto estadounidense: la segunda parte de El valle del terror se desarrolla en un pueblo minero de Pennsylvania. También en Los detectives salvajes se hallan dos novelas en un mismo texto. Una de ellas, la que se lee en las partes primera y tercera, es un thriller centrado en los detectives y en el que el enigma corresponde al paradero de Cesárea Tinajero, quien, por lo demás, no resulta mucho más difícil de localizar que la Betty Mayfield de Playback, de Chandler. La otra historia, correspondiente a la segunda parte, se incorpora en cambio al repertorio de la novela enigma, donde el misterio, tal como en la novela de Conan Doyle, lo constituyen los personajes que en la contraparte desempeñan el papel de detectives. A ello se agrega la inversión del orden de las historias: si en El valle del terror la novela enigma comprende las partes primera y tercera y la novela de detectives la segunda, en la novela de Bolaño ocurre justamente al revés.

${ }^{5}$ Para Carl Malmgreen, la diferencia fundamental entre la novela enigma y el género negro estriba en que aquélla supone un mundo centrado mientras que éste se desarrolla en un universo carente de centro, donde "mundo centrado" se refiere a aquel "en el que los efectos pueden conectarse con las causas y los signos externos conducen a las condiciones internas" (13), un mundo "ordenado, estable, resistente al cambio y relativamente libre de contingencias" (14). En un mundo de esta clase, resulta preciso que el crimen obedezca a una motivación sólida y precisa. Por su parte, los detectives de la novela negra "saben que el caso de asesinato que más fácil resulta solucionar es aquel con el cual alguien ha tratado de pasarse de listo; el que realmente les preocupa es el asesinato que se le ocurrió a alguien dos minutos antes de llevarlo a cabo" (Chandler 377). Contrario a esto, en la novela de Bolaño la historia enfocada en los detectives (partes primera y tercera) se incorpora a un universo en el que reinan la causalidad y la estabilidad de los signos: "los ventanales de una zapatería de la calle Madero me dieron la réplica cabal de mi imagen interior - dice García Madero, subrayando la correspondencia significante-significado-: un tipo alto, de facciones agradables, ni desgarbado ni enfermizamente tímido" (122), mientras que la novela enigma (segunda parte) se desarrolla en un mundo gobernado por la contingencia, un mundo de "sudamericanos perdidos en Europa", de "mexicanos perdidos en Beersheva" y americanos "perdidos en el gran caos americano".
} 
las operaciones efectuadas socavan la isotopía del género detectivesco hasta desarticularla por completo. ${ }^{6}$ Se trata de lo que los formalistas rusos conciben como refuncionamiento cómico de un procedimiento mecanizado (Campesino, "La parodia" 255-57), donde "cómico" se refiere no tanto al efecto de provocar la risa, que desde luego puede haberlo, como a la desacreditación de que son objeto los personajes y que, dado el caso, se traduce en una reducción de la risa carnavalesca (Bajtín, Dostoievski 242-45).

Ya en el siglo XVII, William Robertson (s. n. p.) detectaba en la parodia una transferencia distintiva de la argumentación que, más tarde, en el XVIII, sería localizada en la atribución de la voz a un sujeto menos serio que el original (Du Marsais 273 ss.; Delepierre 10; D'Israeli 454), como sin duda lo son García Madero, Ulises Lima y Arturo Belano en relación con Watson y Holmes y con Dupin y su acompañante. No que sus acciones no puedan tener consecuencias serias y hasta fatales, sino que van de la mano de una atribución insuficiente que subraya la desproporción entre el modelo y su réplica. Esta insuficiencia la identifica Yuri Lotman cuando señala que, en la parodia, la única estructura visible corresponde al desnudamiento mismo del cliché, mientras que el refuncionamiento queda oculto, siendo el lector el encargado de ponerlo en marcha, a manera de contraestructura, sobre la base de su propia competencia retórica. Ahí donde toca, por cierto, al lector descubrir el misterio oculto tras el desnudamiento, salta a la vista el paralelismo entre el género de detectives y el funcionamiento mismo de la parodia. En ambos casos se observa el desarrollo paralelo de dos secuencias temporales distintas; una de ellas, oculta, conduce a la comisión del crimen, de un lado, y del otro al desnudamiento del cliché, mientras que la otra se halla a la vista y su función ulterior

\footnotetext{
${ }^{6}$ En virtud de las inversiones mencionadas, la novela de Bolaño supera a El valle del terror en dos aspectos. Perfecciona, primero, el procedimiento de resignificación convirtiendo el presente de la historia en pasado y el futuro en presente, y concluyendo el texto, en el pasado, con el acontecimiento que da pie al misterio: si en la novela de Conan Doyle la resignificación acaba al final de la segunda parte y el epílogo que le sigue, aun dejando un cabo suelto, le confiere un cierre meramente administrativo a la investigación, Los detectives salvajes concluye con el acontecimiento de mayor peso en cuanto a resignificación del presente por el pasado se refiere, con lo que la apertura final de la novela, siendo mayor, exige del lector una actividad interpretativa más intensa. Y, segundo, dado que el valor de la resignificación se desplaza del orden temporal al carácter mismo del acontecimiento, Bolaño implementa un enlace dramático entre ambas historias y, más aún, entre los universos que las enmarcan.
} 
consiste en desentrañar el misterio de aquélla. De otro modo: ante toda parodia, el lector se comporta como detective para solucionar el misterio relativo al desnudamiento, descubriendo los motivos que condujeron a su comisión, el agotamiento del género, por ejemplo, pero también la admiración de sus máximos exponenetes, y sobre todo el método mediante el que se cometió, en especial tratándose de un crímen en el que, como el mister Douglas de El valle del terror, el asesino se hace pasar por la víctima. Por cuanto al método del detective, cabe señalar que se construye sobre una plataforma retórica contemporánea cuyos procedimientos resultan más convincentes que los del modelo y que en el caso de Los detectives salvajes corresponde, por una parte, a la novela de adolescentes, con el Silvio Astier de Artl a la cabeza, ${ }^{7}$ y por la otra a las memorias del escritor en el exilio, donde las pistas conducen, en primera instancia, a Antes que anochezca, de Arenas.

Lo anterior podría quedar en un plano meramente especulativo si no fuera porque, al proyectarla, al contrario que en Conan Doyle, al futuro, el propio Bolaño convierte al lector en el detective de la segunda parte de su novela, instándolo a resolver el misterio que envuelve a los protagonistas a partir de las declaraciones de una serie de testigos que, no habiendo presenciado la comisión del crimen, aportan sin embargo, así en el cuento de Poe, pistas fragmentarias cuya suma debiera alcanzar para descubrir lo que se oculta tras el errático comportamiento de aquéllos. Las más evidentes: la mención de una sociedad secreta que supuestamente persigue a Lima y a Belano durante veinte años - los mismos veinte años que deben escapar de sus perseguidores los asesinos de las dos novelas de Conan Doyle- y el énfasis puesto de continuo en el carácter siniestro de los protagonistas.

\section{El crimen de la escritura}

Como bien señala Bouché (186), toda parodia comprende una reflexión sobre la escritura que, en adición a la victimación del modelo, reviste un carácter negativo anclado a la rivalidad entre los que, atento a Kristeva, el francés llama órdenes de la ley y del deseo. ${ }^{8}$ Con esta

\footnotetext{
${ }^{7}$ Cabe preguntarse, por cierto, si el título de Bolaño no guarda alguna relación con El juguete rabioso.

${ }^{8}$ Entre los muchos nombres que han recibido, a lo largo de la historia, estos dos ejes, cabe 
dupla, Bouché supera a su colega en la medida en que la lógica poética que ésta extrapola de Bajtín se desplaza únicamente por el eje positivo (del 0 al 2, donde el 1 corresponde a lo anotado y el 2 al comentario de lo anotado), cuando que la negatividad del deseo trasciende su mera oposición con la ley, a la que precede y propicia. ${ }^{9}$ Toda vez que emerge como paradigma de la ley, la única negatividad a que aspira el continuo lógico de Kristeva será de carácter formal, sustitutivo. ${ }^{10} \mathrm{El}$ orden del deseo posee, en cambio, una negatividad sustancial que opone a la ley, a lo objetivo, no una segunda opinión sobre lo legislado, sino su carne viva (Campesino, Estética 113-63); o, de otro modo, que se opone no porque la ley esté mal o sea mala, que de raíz está bien, es buena, sino porque, precisamente por ser buena, por ser lo bueno, la ley se opone al deseo, que de raíz está mal, es malo o, con mayor justicia, lo malo. ${ }^{11}$

mencionar la oposición entre necesidad y pasión que, según Rousseau, pone en marcha las inclinaciones sociales del hombre (Derrida, De la gramatología 274 ss.)

${ }^{9}$ Con cierta razón argumenta Derrida que el incesto no es tal hasta que se lo prohíbe, lo que de ningún modo descarta la recurrencia, anterior a la interdicción, de la endogamia; antes bien, la confirma (330). La ley nombra al pecado, cierto, pero el acto pecaminoso, aún sin nombre, es consecuentemente capaz de suscitar la interdicción. La conservación de la especie es anterior a toda moral (332); antes dice el Antiguo Testamento "creced y multiplicaos" que "no desearás a la mujer de tu prójimo".

${ }^{10}$ Baudrillard detecta esta carencia en la función derivada atribuida por Marx al valor de cambio, en oposición a la función "natural", "objetiva", del valor de uso, al que a su vez trata de abstracción, "la del sistema de las necesidades, que adopta la evidencia falsa de un destino concreto, de una finalidad propia de los bienes y de los productos" (Baudrillard, Crítica 149), pero incurre en el mismo error al reducir la cuestión a la simetría de la forma/objeto y la forma/ mercancía (154). Al empatar el valor de cambio del producto con el significante del signo, y su valor de uso con el significado del mismo (166 ss.), el francés pierde de vista los niveles sustanciales de cada plano semiótico, justamente los que atañen a los valores asignados al cambio y al uso, ceguera que incluso lo conduce a fundir significado y referencia (176 ss.) Más valdría decir que, ahí donde el cambio y el uso corresponden, respectivamente, a las formas del significante y el significado, es decir, al sistema, los valores del objeto y la mercancía, en el mismo orden, se asignan sustancialmente en el proceso.

${ }^{11}$ No alcanzan estas páginas para dar cuenta de las referencias al deseo y sus correlatos como origen del mal contenidas en el corpus de las religiones semíticas; baste, para el caso, lo expresado por san Agustín, para quien todo pecado proviene de la voluntad humana ( $D e$ libero arbitrio 3.17.161-69). El postulado rebasa, de hecho, el ámbito teológico-religioso y se instala, expresado abierta o indirectamente, en el centro de la reflexión filosófica de occidente a propósito de la ética. Sócrates lo explica vagamente en el Protágoras (352a-58a) de Platón y en los Memorabilia (3.9.4) de Jenofonte, y con mucha mayor precisión en la República (430d-48e), donde se incorpora a la teoría platónica del alma tripartida, mientras que Aristóteles, para quien resulta de suma importancia, le dedica el libro séptimo de su Ética nicomáquea. Por lo que se refiere a la modernidad, Kant se ocupa de él en sus Lecciones de ética (178-87) y, aunque en las cuestiones formales lo refuta duramente, en lo sustancial lo secunda Schopenhauer, para quien la moral constituye "un medio que ha sido inventado para una mejor domesticación del egoísta y malvado género humano" (247). Desde una plataforma vindicativa, Nietzsche lo llamará voluntad 
Hay, pues, que tener malicia para, una vez notado el error, repetirlo en lugar de corregirlo; más aún, hay que tenerla para señalar el error mediante su repetición, como sin duda hace Lautréamont según nos explica el propio Bouché.

La victimación del modelo — de la que, caso de Bolaño, me he ocupado brevemente- está presente, en mayor o menor medida, en toda parodia que se precie de serlo. En una línea afín a la teoría de Linda Hutcheon, David Kiremidjian llega a calificar la Batracomiomaquia de "parodia pura o absoluta", en tanto que, asegura, "no parece implicar que haya imperfecciones fundamentales en la concepción o la ejecución de la Ilíada" (233-34), pasando por alto que, sin ir más lejos, la caprichosa abstinencia de participar en la gesta de ranas y ratones por parte de los dioses hace eco de la arbitrariedad con que éstos intervienen en la gesta homérica. Ahora bien, al asumir por sí misma y de manera consciente las consecuencias del error (los intereses de los dioses determinan el desenlace de la guerra), la épica burlesca da un salto equivalente al que plantea Kierkegaard entre la ética de Sócrates, donde el mal se deriva de la ignorancia (Hipias menor 373b-76a; Eutidemo 281e; República 380d-81d), ${ }^{12}$ y la moral cristiana como la entiende su Anti Climacus, para quien, "después que una revelación de Dios nos ha explicado su naturaleza, el pecado es, en presencia de Dios, la desesperación en la cual no se quiere ser uno mismo o la desesperación en la que se quiere serlo" ( Platón 140). Más allá del matiz teológico, el danés se refiere a la conciencia del pecado, que sume al sujeto en la desesperación escindiendo su voluntad, pues, ya lo decía Sócrates, "nadie que sepa y que crea que hay otras cosas mejores que las que hace, y posibles, va a realizar luego ésas, si puede hacer las mejores" (Protágoras 358bc). Amén de dramatizar la falta, de ponerla en escena, la comisión voluntaria del pecado pone de relieve el mal inherente al acto. Incluso Sócrates admite que la falta deliberada resulta más reprobable que la que

de poder y unas décadas después, atribuyéndole la paternidad de la religión y la moral, Freud lo situará en la base de su teoría de la neurosis $(229,496-97)$, así como en el origen de lo ominoso, en cuyo caso lo denomina retorno de lo reprimido (2483-505). Superando, por mucho, la esfera de la reflexión, a lo largo de la historia el correlato deseo-mal ha justificado cualquier cantidad de totalitarismos, encontrándoselo, afirmado o contradicho, prácticamente en cada resquicio de la concepción que el ser humano se ha hecho de sí mismo.

${ }^{12}$ En su artículo "El intelectualismo ético de Sócrates", James Colvert ofrece una exposición cabal de esta problemática. 
proviene de la ignorancia, en especial porque, si la virtud es sabiduría, "el que comete errores voluntariamente y hace cosas malas e injustas [...] no puede ser otro que el hombre bueno" (Hipias menor 376b).

De manera que cuando un autor comete con su escritura una falta deliberada, enfatiza el mal inherente al acto de escribir, lo que va de la mano de una dramatización de la escritura. El concepto pasaría por virtual si no fuera porque, ya en el siglo v a. C., en su Espectáculo del alfabeto (Ateneo 10.453c-54a), Calias incluye un coro de mujeres que, representando las letras del alfabeto griego, acompañan a una mujer, ¿la escritura personificada?, que se confiesa embarazada pero que, por pudor, en lugar de pronunciar el nombre de su cría, describe las letras que lo integran: una de ellas consta de un palo largo y recto en cuyo centro, una a cada lado, se cruzan dos líneas pequeñas curvadas hacia arriba; la otra, de un semicírculo con dos patas. Se trata de la psi y la omega, cuya irónica exposición por la vía perifrástica obedece, por una parte, al hecho de que, siendo de origen jónico, ambas letras resultaban vulgares en la órbita ateniense y, por la otra, aunque en estrecha relación con esto último, a la sugerente imagen que resulta de su combinación pictográfica. ${ }^{13}$

En su libro Abusos y admoniciones, Aníbal González revisa los avatares de esta actividad grafofóbica que, en el marco de la literatura hispanoamericana, rastrea hasta la colonia. Sostiene este autor que la jerarquía lingüística otorga preeminencia al habla, que ve como fuente de verdad y bondad, mientras que "la palabra escrita siempre cae bajo la sospecha de ser una forma potencialmente subversiva, malévola y rebelde del lenguaje" (12). Incluso Derrida, el más fiero defensor de la escritura, subraya una y otra vez su naturaleza perversa y virulenta, cualidades sobre las que, de hecho, edifica su vindicación..$^{14}$ No sería

${ }^{13}$ No fue exclusiva de Calias la dramatización del alfabeto griego. La emplearon también Eurípides, en su Teseo, y Sófocles en su drama satírico Anfiaraos (Svenbro 91-92).

${ }^{14}$ Atendiendo con especial interés a los postulados de Rousseau, a quien dedica el grueso de su De la gramatología, Derrida da seguimiento a esta grafofobia desde los comienzos del pensamiento propiamente filosófico de occidente hasta el estructuralismo contemporáneo de un Saussure y un Lévi-Strauss. Ya en La farmacia de Platón se refería a la actitud del Fedro para con la escritura, que Sócrates compara con un fármaco que, sin curar el mal como una verdadera medicina, se ocupa simplemente de aliviarlo ocasionando, a cambio, otros perjuicios. A propósito, Sócrates trae a cuento un mito egipcio según el cual Theuth, tras haber inventado, entre otras artes y técnicas, la escritura, se presentó con el rey Thamus describiendo su creación como un fármaco que haría a los hombres más sabios y memoriosos, a lo que el soberano respondió con escepticismo que, 
por casualidad que los grandes reformadores del cristianismo, que comenzaron todos proponiendo la libre lectura de la Biblia, terminaran por condenarla reaciamente, sobre todo tratándose del vulgo, al que, a cambio, le era recomendable escucharla de unos labios autorizados (Gilmont 339-46). ${ }^{15} \mathrm{Si}$ ello ocurre con los textos canónicos, el caso de la ficción resulta en grado sumo escandaloso, ya que, al abuso de la escritura, "en tanto que ésta debería manejarse cuidadosa y sabiamente, como el fuego u otra fuerza potencialmente destructora", agrega el abuso mediante la escritura, "en tanto que hacer uso de ésta para fines que no sean estrictamente comunicativos implica una ignorancia culpable e irresponsable de los orígenes violentos de la escritura y sus poderes negativos" (González 21). ¿Qué ocurre, me pregunto, cuando la culpabilidad de la escritura no es ni ignorante ni irresponsable sino todo lo contrario, cuando pasa deliberadamente de la potencia destructora

por el contrario, la escritura convertiría a los hombres en falsos sabios, toda vez que los induciría al olvido, obligándolos a acceder a la memoria, registrada en caracteres extraños, desde fuera (274d-275b). Dado que para Sócrates sólo es posible acceder a la verdad por la vía propia, puesto que ella está en uno, se comprende la concepción de la escritura como fuente originaria del mal. Por hacer "pasar un veneno por un remedio", dice Derrida, en el Fedro "se le reprochará al invento del fármacon el sustituir el habla viva por el signo sin aliento, el pretender prescindir del padre (vivo y fuente de vida) del logos, el no poder responder de sí más que una escultura o que una pintura inanimada" (La diseminación 136, 145), sustitución en todo semejante a aquella mediante la que, supone Freud, los hijos de la horda primitiva habrían suplantado al padre primigenio. En concreto, Maryanne Wolf (90-100) identifica en el Fedro tres grandes críticas de la escritura, que atañen a su rigidez, a la destrucción de la memoria y a la pérdida de control sobre el lenguaje. En Rousseau, la demonización de la escritura llega a situarse en el centro de la reflexión etnográfica y pedagógica sobre el lenguaje, posición que heredarán los sistemas de Saussure y Lévi-Strauss. Tan sólo al primero, el horror a la escritura lo condujo a desarrollar una teoría anagramática de la poesía latina, en especial de los versos saturnios, con el objeto de asignar a los sonidos del poema un sentido marginal con respecto al que propician en la cadena gráfica, lectura encaminada, en cierta medida arbitrariamente, al desciframiento semántico de las combinaciones de fonemas y no de letras: "No se tratará, pues, de redistribuir conjuntos limitados de signos visuales que se prestarían al enunciado ortográficamente correcto de un «mensaje» considerado primitivo; no se intentará leer el poema como si el autor hubiera comenzado por escribir, con las mismas letras, un verso totalmente distinto" (Starobinski 26).

15 Incluso la cábala, que atribuye el inicio de la creación a la invención de las letras y que, por tanto, adopta una postura neutral a propósito de la escritura, fuente, en todo caso, tanto del bien como del mal (Zohar 1.2b-3b), reconoce el peligro de la falsa interpretación (4b-5a), por eso subraya el imperativo de que únicamente los más autorizados lean las escrituras y por ese medio las compartan con el pueblo (2.206a-b), para el que, dado que Yahveh creo el mundo con el aliento de su voz (1.156a-b), queda reservada la tradición de la Torah oral. En cualquier caso, como el lector de parodias, el cabalista está llamado a descubrir un texto oculto dentro de otro texto (2.98b). 
de la forma a la destrucción mediante la forma? En tal caso, se obtiene una parodia.

La reflexión paródica sobre la escritura se desplaza, pues, de lo formal a lo sustancial: de la detección del mal en cierta clase de escritura (sus clichés, sus mecanizaciones...) a la asunción de la escritura como fuente del mal, como origen de la locura y el crimen. ${ }^{16}$ De ahí su paralelismo con, justamente, el relato detectivesco, donde el crimen suele comprender dos facetas del mal: de un lado la maldad de la víctima, motivo suficiente (en un sentido formal, jurídico) para que alguien deseara su muerte $y$, del otro, la maldad del asesino, donde el deseo se sustancia, convirtiéndose en una realidad material. Este excedente se observa en el manejo del tiempo por parte de Bolaño. En Conan Doyle, el misterio se sostiene artificialmente de una inversión temporal, bien mediante la irrupción, justo antes de resolverse el caso, de un relato sobre el pasado, así en Estudio en escarlata, o bien, como en El valle del terror, incorporando dicho relato al final pero ocultando las claves de la relación entre ambos periodos, inversión que, en el cónclave del género (si la novela de detectives se contara en orden cronológico no tendría razón de ser), no sólo no abona al significado de la historia, sino que lo difiere, lo socava. ${ }^{17}$ Ahí donde el relato de detectives oculta, pues, su falsedad innata tras un recurso sintáctico típico de la novela, en contraste con su temática de corte jurídico, al diferir el crimen hasta el último momento, Los detectives salvajes socava la sintaxis detectivesca en beneficio del significado novelesco, sostenido, a la inversa que allá, por el misterio. En un caso se trata de simular, de ocultar mediante el disfraz una carencia propia; en otro, de obliterar la propia virtud por la vía de la disimulación. ${ }^{18}$

\footnotetext{
${ }^{16}$ Sin recurrir en absoluto a Bouché, Robert Phiddian (13-25) extrae la misma conclusión de sus lecturas de Swift, sobre cuya base acuña el binomio textualidad ilegítima. A quien sí recupera Phiddian es a Derrida cuando define la parodia como una clase de escritura que, borrándose a sí misma, desfigura a sus modelos.

${ }^{17}$ Cosa contraria ocurre en novelas como A sangre fría, de Capote, y Las muertas, de Ibargüengoitia, donde el orden natural de los sucesos determina la perspectiva periodística.

${ }^{18}$ Un caso, el de la alazonía; otro, el de la ironía (Aristóteles, Ética nicomáquea 4.7.1127a-1127b).
} 


\section{El mensaje del asesino}

Muchas y muy variadas son las dramatizaciones del crimen de la escritura que la parodia literaria ha puesto en marcha. Ahí están el Arcipreste de Hita, componiendo su pequeña escritura "en memoria de bien", pero consignando en ella "algunas maneras e maestrías e sotilezas engañosas del loco amor del mundo, que usan algunos para pecar"; ahí Tristram Shandy, objetando y cuestionando hasta la saciedad su propia escritura, y con él los seis personajes de Pirandello, huérfanos de autor. En el Quijote, además de la locura del protagonista y las continuas referencias peyorativas al supuesto autor del manuscrito "original", Cervantes recurre a una quema de libros, aunque para ajusticiamientos de la escritura, Bolaño se pinta solo, dando muerte violenta a quien en su novela constituye la mismísima personificación de la poesía.

Ausente, estrictamente hablando, de su caligrama, única obra de su autoría que aparece en la novela, en Los detectives salvajes lo literario se desplaza al personaje de Cesárea Tinajero, cuya enigmática caracterización invita a Lima y a Belano a salir, sin motivo aparente, en su búsqueda. Cesárea representa ese absoluto que todo adolescente de novela espera encontrar y que, tratándose de adolescentes poetas que leen a Marx y a Rimbaud hasta secarse los sesos, no puede ser otro que la poesía misma. La poesía vista, en particular, desde la óptica de las vanguardias; es decir, como una vieja lugareña, gorda y obtusa, que en sus años de esplendor se atrevió a desafiar a Germán List Arzubide, el más desafiante de los poetas. Pero si Cesárea encarna la poesía, entonces su fallecimiento representa la muerte de la poesía, un correlato que se materializa como sacrificio toda vez que, con la suya, el personaje evita la muerte de los protagonistas. James George Frazer dedica su atención a la transferencia simbólica del mal que entraña todo sacrificio ritual, cuya práctica, por la vía de una víctima expiatoria, identifica en diversos contextos, entre los que destacan los de Grecia y Roma y, en especial, el de las saturnalias (608-61). De lo que no se ocupa sir Frazer es del salto que dan, al respecto, una moral como la cristiana o una ética metapsicológica como la de Freud, y que consiste en que, a la expiación del pecado original mediante el sacrificio de una víctima propiciatoria, se sobreviene una nueva culpa, la del sacrificio 
mismo, imposible de expiarse por conducto de terceros. Se trata de la conciencia del pecado que cargan secretamente Lima y Belano en la segunda parte de la novela y en virtud de la que la notable recurrencia del adjetivo "siniestro", que aparece unas quince veces en la novela, ${ }^{19}$ resulta de todo menos casual, conformando, como hace, la expresión léxica del carácter maldito de los personajes. "Un individuo siniestro señala Eugenio Trías - es portador de maleficios y presagios funestos: cruzarse con él lleva consigo un malfortunio" (109-10), de donde la desgracia que pesa sobre el editor Lisandro Morales, hasta la locura inclusive, a partir de la publicación de la antología de poesía preparada por Belano, episodio que aquél concluye con un lacónico "La literatura no vale nada" (Bolaño 301), y también sobre Xosé Lendoiro desde que observa a su hija sosteniendo relaciones sexuales con el chileno, maldición que lo conducirá a la enfermedad y, ante la muerte inminente, a concluir: "Hasta aquí llega la poesía, esa mala pécora que me ha acompañado a traición durante tantos años" (448).

Poco valdría, no obstante, la conciencia del pecado si, una vez revelada la naturaleza del mismo, se diera únicamente como consecuencia del acto y no a la inversa. Ahí donde, a su muerte, la poesía se ausenta de las vidas de Lima y Belano, abandono que, como el del padre o la madre, ambos intentan compensar por medio de la inmadurez y la desproporción, la maldición que los persigue proviene de su culpabilidad en cuanto a la muerte de Cesárea: culpabilidad material, dado que conducen hasta ella a Alberto y su matón, y culpabilidad simbólica, relativa a su enérgica participación en un movimiento de vanguardia incendiaria que, como toda vanguardia, aspira a aniquilar la gran poesía. De las dos, me parece que la segunda resulta una carga no menos pesada, en cuyo caso, al retornar, lo reprimido precipita a los personajes rumbo a la ignominia, no en balde asegura Trías que "en lo siniestro parece producirse en lo real una confirmación de deseos y fantasías que han sido refutados por el choque del sujeto con la realidad" (51). En su libro sobre La literatura y el mal, Bataille enfatiza la oposición entre sacrificio y maleficio, siendo que aquél persigue el bien supremo y, al mismo tiempo, fortalece el vínculo social, mientras

${ }^{19}$ Tan sólo la página 426 contiene cuatro de ellos. 
que, sin poder distanciarse del instinto que lo motiva, éste constituye un elemento negativo por derecho propio ( 73 ss.), derecho que no puede recaer sino en el sujeto. Ambos se alimentan de la aterradora proximidad de la muerte, con la salvedad de que, por más honda que se abra la falla entre uno y otra, el fin último del sacrificio es preservar la vida, cuando que el maleficio se encamina desesperado rumbo a su término.

Y, sin embargo, el origen de la maldición que pesa sobre el Lima y el Belano adultos va también de la mano del sacrificio existencial por el que debe pasar todo adolescente de novela, dejando atrás su inocencia infantil al enfrentarse por primera vez no tanto con el mal en sí como con la conciencia del mal, donde conciencia y consecuencias materiales son casi sinónimas. En dado caso, el mal atribuido a la víctima se transfiere al victimario; hay, pues, una transustanciación. El espíritu adolescente, deseoso de traspasar el umbral de la vida adulta, rechaza categóricamente la inocencia pueril, pero al desembarazarse de ella se topa de frente con la muerte, de la que en adelante tendrá que escapar a toda costa; de ahí que, tal como le ocurre en Sonora a los personajes de Bolaño, lo que inicia como pesquisa termine como fuga desesperada, como sacrificio vital en pos de la soberanía. ${ }^{20}$ Bataille (191-93) observa este movimiento en un relato de Kafka en el que, en adición, identifica un tercer estadio, que corresponde al momento en que la soberanía se desprende de la culpa y la miseria para enfrentarse con la muerte real sobre la base de una libertad sin objeto, de una libertad que retorna a la primera inocencia. Más que en ningún otro aspecto, en ello se diferencian los destinos de Lima y Belano, ya que la novela abandona al primero en la etapa de la soberanía culposa, dejándolo cubierto por el velo del maleficio, mientras que el segundo concluye su participación dispuesto a morir como un niño que juega a la guerra. ${ }^{21}$

Cabe preguntarse si semejante tránsito no guarda un parecido significativo con el que recorre el propio Bolaño, y con él todo parodiarum scriptor, al pasar del sacrificio de una víctima expiatoria, en este caso la narrativa detectivesca, al autosacrificio que supone

\footnotetext{
${ }^{20}$ James Marsh explica esta dicotomía en términos de la interacción de determinación e indeterminación en el seno del sujeto, dialéctica que denomina ironía de la libertad (479-85).

${ }^{21}$ La problemática del mal y la libertad la tratan extensivamente Rüdiger Safranski en El mal o el drama de la libertad y Alvin Plantinga en "God, Evil, and the Methapysics of Freedom".
} 
apropiarse del pecado de la víctima y, con él, de sus consecuencias fatales, salto análogo, por lo demás, al que media entre la culpabilidad y la culpa o, de otro modo, entre el pecado y la conciencia del pecado. ${ }^{22}$ De ser así, la semejanza resolvería de tajo la añeja discusión en torno a las motivaciones de la parodia y a la aparente paradoja que surge de colocar frente a frente la aversión y la admiración (D’Israeli 547; Marmontel 31-32; Hutcheon, A Theory 2, 26, 33), pues si el análisis paródico expía sus propias fallas estructurales mediante el sacrificio de una víctima expiatoria, en lo que toca a la síntesis correspondiente, al mensaje articulado de tal forma, la parodia se convierte ella misma en víctima propiciatoria que, con su autoinmolación, a un tiempo lava la culpabilidad del modelo y asume una culpa auténtica, un auténtico maleficio del que ya no podrá desprenderse. ${ }^{23}$ Puede que Ricoeur invierta la terminología, llamando culpa al pecado y culpabilidad a la conciencia del pecado, pero ello no le impide concluir que la segunda "exige que el mismo castigo se convierta de expiación vindicativa en expiación educativa, o, para decirlo en una palabra, en «enmienda»" (Finitud 261). Cierto, así de Sócrates y Platón como de Kant, Shopenhauer y Bataille, por no decir que de la gran mayoría de los moralistas occidentales, se deduce que, al pecar, el hombre bueno se sacrifica por un bien superior, sin olvidar, claro, que como resultado de esta conciencia, se echa sobre los hombros un maleficio imborrable: su identidad, la desesperación de rehusar a sí mismo al momento de afirmarse, y que hermosamente resumen los siguientes versos de Martínez Rivas (4):

\footnotetext{
${ }^{22} \mathrm{Si}$ en otros términos, Maeztu (52-61) plantea una semejanza análoga entre don Quijote y Cervantes.

${ }^{23}$ René Girard inicia La violencia y lo sagrado advirtiendo esta doble naturaleza del sacrificio ritual, que ya Hubert y Mauss situaban en el carácter sagrado de la víctima, sagrada, precisamente porque se la sacrifica. Supera, sin embargo, el formalismo de sus maestros ahí donde desplaza su atención del intercambio inherente a la expiación sacrificial, donde la víctima sustituye al victimario, al auténtico carácter religioso del sacrificio que, sustituyendo la víctima por el victimario, reserva a la institución el derecho legítimo a la violencia. En términos generales, dicha sustitución material atraviesa su teoría del deseo mimético en su tránsito de la filología a la antropología (de Mentira romántica a El chivo expiatorio), una problemática que, al margen de su gran utilidad para el análisis formal, incluso la angustia de las influencias propuesta por Harold Bloom pasa por alto.
} 
Una antigua necesidad: el holocausto

del propio ser. El deseo

de imponeros algo perenne y tribunal.

Y otro. Más rabioso,

más trémulo; el deseo de tener un pasado.

Un pasado por fin que oponer al maldito presente.

Un pasado adornado con todas sus plumas.

Con su perspectiva de adecuada jerga,

con sus categorías históricas y su problematismo crítico-cultural

precisado en función de una radical revisión de...

Y la larga, accidentada, alucinante teoría de los géneros y los estilos.

Corresponde este maleficio a la imposibilidad de detener la marcha de la significación, al mandato de ser un suplemento más en la interminable cadena de los suplementos de que habla Derrida, cuya secuencia anuncia la necesidad "de un encadenamiento infinito que multiplique ineluctablemente las mediaciones suplementarias que producen el sentido de eso mismo que ellas difieren" (De la gramatología 201). Y un poco antes: "El suplemento transgrede y a la vez respeta lo prohibido. Es lo que permite también la escritura como suplemento del habla; pero ya también el habla como escritura en general" (198).

En contraste con las partes primera y tercera, pletóricas de entusiasmo por la poesía y la literatura, en la segunda parte de Los detectives salvajes la reflexión negativa sobre la escritura se instaura como determinante de los personajes. Al entrar en contacto con Lima y Belano, portadores de un virus latente, los declarantes contraen el incurable mal de la escritura, un contagio que se verifica en el hecho de que su escritura da a conocer a los protagonistas ocultando, a un tiempo, el misterio detectivesco, fuente de una enfermedad cuyos síntomas, además de en los ya mencionados Lendoiro y Morales, se manifiestan en Auxilio Lacouture, Pelayo Barrendoáin y Jacobo Urenda. Después de pasar varios días escondida, leyendo y escribiendo poemas, en un baño de la Facultad de Filosofía y Letras durante la ocupación militar de la UNAM en 1968, Lacouture arroja al inodoro el papel higiénico en que había escrito unos versos e, inconscientemente, 
tira de la cadena, tras lo cual, atemorizada al escuchar el ruido del agua, consigna: "Pensé: la vanidad de la escritura, la vanidad de la destrucción. Pensé: porque escribí, resistí. Pensé: porque destruí lo escrito me van a descubrir, me van a pegar, me van a violar, me van a matar. Pensé: ambos hechos están relacionados, escribir y destruir, ocultarse y ser descubierta" (198). La intervención del segundo, sin tanto alcance, se limita a su presencia en la Feria del Libro de Madrid, donde, afectado por los antidepresivos, reflexiona sobre las mujeres que le solicitan autógrafos y entre las que menciona a "la que se interesa por la literatura sin imaginarse los infiernos que se esconden debajo de las podridas o impolutas páginas" (496). De mayor relevancia, hacia el final de la segunda parte el personaje de Urenda se ve obligado, junto con Belano y otros periodistas, a pasar la noche en un pequeño pueblo de Liberia azotado por la guerra civil. "Todas las lenguas, entonces, me parecieron aborrecibles", recuerda del momento en que, hacinado en un galerón en el que también pernoctaban algunos nativos rebeldes, escuchaba fragmentos de las conversaciones en distintos idiomas, y concluye: "Todas las lenguas, todos los murmullos, sólo una forma vicaria de preservar durante un tiempo azaroso nuestra identidad" (543). Y por si no quedare claro, Andrés Ramírez, uno de los pocos personajes que no contraen el mal, de hecho, el único a quien le sonríe la fortuna - el único, también, que dirige su declaración a Belano-, se gana la lotería en dos ocasiones poniendo en práctica su obsesión por la escritura numérica, una vacuna que le permite experimentar las letras sin sufrir el suplicio que infligen al resto de los personajes.

\section{Ladrón que roba a ladrón...}

Con todo, lejos de agotarlo o imprimirle un colofón, en la parodia la reflexión negativa sobre la escritura sirve de antesala al significado, proveyendo la plataforma sobre la que se construye la temática $o$, de otro modo, desde la que la obra extiende sus redes hacia lo real. En la parodia, lo que para Pascual Buxó constituye el "pasaje de la coherencia léxico-sintagmática a la coherencia tópica" del texto (50), se da por intermedio de una tematización de aquélla, de una dramatización de la escritura que pone de relieve su mal inherente. Si, como asegura 
Safranski, el mal se manifiesta a un tiempo como tema y como condición interna de la producción artística (194), la parodia suma a la operación un elemento intermedio: la tematización de la condición interna de su productividad.

El origen del mal, había yo dicho a propósito de Bouché, recae en el deseo, cuya cinética, tratándose de la ficción, se traduce en el impulso de crear realidades imaginarias opuestas a la realidad real, por eso dice Castilla del Pino que "para que don Quijote tenga su razón de ser, que no puede tenerla en la realidad real, tiene que inventarse otra realidad, un mundo propio, singular" (52). Un mundo que, en adendo, se empeña en otorgar categoría de real a algo que ni la tiene ni debe tenerla, en sustanciar una forma a la que ha despojado de su sustancia original, comportándose como el Marqués de Bradomín de que habla Alfonso Reyes y que, ante cada lance, abre los libros y se dice: "Veamos lo que hizo en caso semejante Don Juan; veamos lo que hizo el caballero de Casanova, para imitarlos aquí mecánicamente" (103). Al margen de las posibilidades de contagio, semejante proceder, huelga decirlo, asume el riesgo de la autoaniquilación, el riesgo de ser consumido por la nada que lo hubo de engendrar. ${ }^{24}$ Se trata de un peligro que, directa o indirectamente, enfrenta toda obra de ficción; de ahí que, cuando Lyotard detecta en la novela el impedimento de expresar el ideal, "puesto que se da un ejemplo en el fenómeno de aquello que no puede propiamente ser «realizado»" $(105),{ }^{25}$ lo cierto es que se refiere al carácter ficticio del relato que, como toda ficción, elimina el sustrato real de la idea. ${ }^{26}$ Cabe, con todo, como hacen Rousseau, Nietzsche y compañía, extender la acusación a la lengua misma, cuyo origen se liga indisolublemente a la figuración, a la representación: "La posibilidad original de la imagen es el suplemento — señala Derrida—: que se añade sin añadir nada para

24 "El deseo devora - dice Safranski-, y el mismo que desea es devorado por el objeto de su deseo" (194).

25 "El demonio — dice Curtius al respecto- también fue poeta, pues escribió los oráculos, que, como es bien sabido, estaban en verso", una idea que el historiador recoge de Justino, para quien las fábulas de los poetas "se inventaron por obra de los espíritus malos para engañar y extraviar al género humano" (773).

${ }^{26}$ Para Adorno, este impulso de autodestrucción es característico de la conciencia, que descubre la contradicción en el proceso mediante el que configura su materia: el pensamiento. "La ratio - subraya - se convierte en irracionalidad tan pronto como desconoce en su necesario desarrollo que la desaparición de su sustrato, por estilizado que se encuentre, es su propia obra, producto de su abstracción" (152). 
colmar un vacío que dentro de lo pleno pide dejarse reemplazar" (De la gramatología 367). Por su parte, al asumir voluntariamente esta doble problemática, la parodia se sitúa en el vértice de la añeja discusión, cuyas simientes germinan ya en Sócrates, entre quienes otorgan al mal un carácter sustancial y aquellos que lo consideran producto de una carencia, ${ }^{27}$ pues ahí donde la forma se sustancia, desaparecen los límites entre el deseo y la falta, entre el impulso y el acto. ${ }^{28}$

No es, desde luego, un salto cuántico el que conduce a la conciencia del pecado y al autosacrificio; se trata, antes bien, de una transición histórica tanto en los términos del propio texto como en los del universo que lo enmarca. Lejos de surgir por generación espontánea, lo que Margaret Rose llama parodia general constituye una suma de parodias específicas que transforma la totalidad del sintagma, dotándolo de autonomía en el marco del gran tiempo (47-53). Amparado en una definición del concepto, si incompleta, bastante plausible, ${ }^{29}$ Dennis Green detecta una considerable cantidad de ironías en los romances heroicos de la baja edad media, mismas a las que, de manera general, asigna las funciones de contraponer, por una parte, la retórica del amor cortés al código caballeresco y, por la otra, de poner a prueba la

${ }^{27}$ La defensa de su carácter sustancial se halla, por ejemplo, en las antiguas religiones dualistas, incorporadas al cristianismo a través de las teologías gnósticas (Eliade y Couliano 1316), y llega hasta nuestros días a través de pensadores como Hobbes (Leviatán 1.11, 13), Sade (156 ss.), Rosenfield (188 ss.) y el propio Derrida (en ello, justamente, difiere de Rousseau). Entre los que reniegan de él, proponiendo que el mal constituye un aspecto del bien o, en cualquier caso, su simple negación, se cuentan Aristóteles (Metafísica 9.1051a), Leibniz (Teodicea 1.104 ss.) y, más recientemente, Zubiri (313 ss.) y Ricoeur (El mal 58 ss.)

${ }^{28}$ San Agustín deja esta cuestión sin resolver, ya que, si bien asegura que todo mal proviene de la privación de un bien (De civitate Dei 9.22), con lo que niega su sustancialidad, lo cierto es que, en su teología de la predestinación, el pecado figura como elemento connatural del hombre, como una falta ontológica que justifica su culpa y su sufrimiento y cuyo origen último recae en el deseo. Intentando salvar el escollo, Kant atribuye un valor cuantitativo a la negatividad del mal, un parámetro suficiente para medir su magnitud descendiente, sin reparar en que la cualidad positiva o negativa asignada a un signo depende de una determinada escala de valores (Blanco Fernández 87-116). Quien parece salir bastante airoso es santo Tomás, que en su De malo $(1.1,2)$ resuelve el asunto por la vía de la lógica aristotélica, mediante la que confirma la realidad ontológica del mal de tres maneras: (1) agregando a las magnitudes positivas y negativas la posibilidad de un intermedio, lo que desacredita la concepción del mal como ausencia de bien, (2) reparando en el cambio sustancial que opera en el sujeto de la corrupción y (3) ejemplificando con el castigo y su doble naturaleza, malo y bueno a la vez, y también por una segunda vía, más acorde con la ética socrática, según la cual no puede desearse sino el bien.

29 “La ironía consiste en un enunciado o en la presentación de una acción o situación en los que el sentido real o implícito dirigido a los iniciados difiere intencionadamente, siendo incongruente con él, del supuesto sentido presentado a los no iniciados" (9). 
verosimilitud del relato. Por su parte, Eduardo Urbina (679) coincide con Green (357-58) en que el germen de la ironía cervantina se encuentra ya en los libros de caballería, y no únicamente de manera potencial, pero le reprocha reducir la parodia a una subespecie estructural de ironía, siendo que, cuando menos en el Quijote, "la parodia da forma y hasta determina cada uno de los usos y sentidos de la ironía”. Llámense ironías o parodias específicas, lo cierto es que su empleo en el romance medieval difiere del de Cervantes en que en el Quijote se multiplica hasta suscitar "la renovada toma de conciencia de los conflictos ideológicos y la deformación de los elementos vitales de una tradición" (Urbina 675), mientras que allá su intermitencia no afecta sustancialmente ni a la isotopía de los textos ni a las convenciones del género, sino que, muy por el contrario, redunda en la búsqueda, por parte de ambos, de un realismo menos idílico.

De igual modo, el germen de la ironía y la parodia de Bolaño brota ya en la ficción detectivesca. Un ejemplo, la incorporación, sin marcadores gráficos, del monólogo interior del detective al cuerpo textual del narrador extra y heterodiegético en El complot mongol (1969), de Rafael Bernal: "En el trayecto no hablaron casi. Este pinche ruso no se dejó abrazar como el gringo. No sé qué pistola pueda traer o qué otro arsenal. Y él muy aguzadito, sabe todo lo que hago" (72), y que en Bolaño halla su reverso en la integración del diálogo al monólogo interior. Ahora que, si de detectives adolescentes e insensatos se trata, ahí está Ana Beddingfeld alegando, tras arriesgar la vida imprudentemente: “¡Yo no soy una colegiala alocada! ¡Soy una mujer!” (183), palabras cuyo sentido irónico, sin afectar en lo sustancial la historia de Agatha Christie, determina no obstante la de Los detectives salvajes.

Lejos de ponerla en entredicho, cuando le dice a su amigo: "Me hace usted pensar en Edgar Allan Poe y en Dupin. Nunca me imaginé que esa clase de personas existiese sino en las novelas" (32), Watson refuerza la isotopía del relato, ya que, a pesar de la ironía de tratarse, en efecto, de un personaje de novela, Holmes se compromete a no comportarse como tal y, con éxito, a no cometer las mismas faltas que sus predecesores, cuando menos no voluntariamente. El episodio, en el que Holmes y Watson comentan sus lecturas detectivescas, guarda una semejanza 
notable con la quema de libros del Quijote, con la diferencia esencial, no obstante, de que si se aplicara el criterio del cura y el barbero a la novela de Cervantes, lo más seguro es que, en términos generales, no se salvaría de las llamas. Tampoco se salvan, como detectives, Lima y Belano. Y no por falta de empeño o coraje, sin los cuales no habrían dado con Cesárea Tinajero ni se enfrentarían, como hacen, con Alberto y su esbirro, sino porque su fracaso está predeterminado por el choque de la realidad real y la realidad imaginaria, por la distancia que media entre el personaje de Cesárea y la fantasía con que figura en la mente de aquéllos. Lejos de designar, como en Frye y Bajtín, una clase de mundos habitada por criaturas extraordinarias (ratones armados hasta los dientes, gigantes orgiásticos, caballos que hablan...), aquí "fantasía" se refiere al momento, al lugar en que el deseo se funde con la idea, con el ideal, si se quiere, para dar paso a lo ideológico, para dar paso a esa ritualización espontánea tan característica del burgués — caso de don Quijote y Emma Bovary y también, estoy seguro, de los consumidores de epopeyas en tiempos de la Batracomiomaquia - y, tratándose de Lima y Belano, también del adolescente. ${ }^{30}$ Con su naturalidad, la muerte de Cesárea supone, en efecto, un perfeccionamiento con respecto a "esos asesinatos imposibles" (225) de que habla el personaje de Simone Darrieux a propósito de sus lecturas, compartidas con Belano, de Agatha Christie, pero no una mejora en sentido detectivesco, puesto que el error de fungir de medio entre el asesino y la víctima resulta imperdonable para cualquier detective (Van Dine 331; Knox 340), sino en el de otra clase de realismo no sólo menos idílica, sino opuesta al idilio. ${ }^{31}$

Y, sin embargo, no se trata de una transparencia del mal según la plantea Baudrillard (90-97), cuya consecuencia sería, como en algunas vanguardias, la dilución de todo valor, el arrasamiento total de la imagen.

\footnotetext{
${ }^{30}$ No en balde Erik Erikson concibe la adolescencia como la etapa ideológica del desarrollo ontogenético de la ritualización (103 ss.)

${ }^{31}$ Esto mismo se observa en Ateneo (5.182a, 186e, 187a ss., 192d-217d), cuyo compromiso explícito de subsanar las deficiencias del modelo va de la mano con la comisión voluntaria de errores de equivalente magnitud. Pues si el de Naucratis condena la artificiosidad con que, en Platón por ejemplo, los discursos se suceden unos a otros y, a cambio, su simposio gana en naturalidad y espontaneidad, lo cierto es que, donde allá se trata, en unas cuantas páginas, un tema elevado de manera puntual, acá se desarrolla una tópica vulgar de forma tan profusa, que la resultante es un fárrago (es probable que los quince volúmenes actuales resuman treinta libros originales) en el que el tema se trivializa para dar entrada a una erudición variopinta e inagotable.
} 
Se trata, más bien, de una transparencia contenida por la forma que, en tanto que contorno, le impone límites y la dota de un carácter sensible (lo que en jurisprudencia se conoce como cuerpo del delito). Puede que posea una sustancia auténtica, una negatividad radical, pero el mal es susceptible de arrojar una imagen, incluso siendo negativa, más aun siéndolo, sólo cuando afecta al hombre bueno, casos de Lima y Belano, caso del propio Bolaño, un hombre que a consecuencia del drama se vuelve, en palabras del vicerrealista Rafael Barrios, "inquietante y seductor" (321). Sin esta coacción de la forma, que impone límites al mal y da cuerpo al delito, ${ }^{32}$ la ficción no podría redimirse, no podría escapar por ningún medio a su propia y voraz irrealidad, pues, como bien dice el personaje de Abel Romero en Los detectives salvajes, "el meollo de la cuestión es saber si el mal (o el delito o el crimen o como usted quiera llamarle) es casual o causal. Si es causal, podemos luchar contra él, es difícil de derrotar pero hay una posibilidad, más o menos como dos boxeadores del mismo peso. Si es casual, por el contrario, estamos jodidos. Que Dios, si existe, nos pille confesados" (397).

\section{Referencias}

Adorno, Theodor. Dialéctica negativa. Trad. José María Ripalda. Madrid: Taurus, 1975. Impreso.

Agustín de Hipona (santo). Obras de San Agustín, vols. 3 y 17. Ed. bil. Victorio Capanaga, Santos Santamarta y Miguel Fuerte. Madrid: Editorial Católica, 1963-. Impreso.

Ateneo de Naucratis. Banquete de los eruditos, 5 vols. Trad. Lucia Rodriguez-

Noriega Guillén. Madrid: Gredos, 1998-2014. Impreso.

Aristóteles. Ética nicomáquea; Ética eudemia. Trad. Julio Pallí Bonet. Madrid:

Gredos, 1985. Impreso.

Aristóteles. Metafisica. Trad. Tomás Calvo. Madrid: Gredos, 1994. Impreso. Bajtín, Mijaíl. Problemas de la poética de Dostoievski. Trad. Tatiana Bubnova.

México: Fondo de Cultura Económica, 2003. Impreso.

Bajtín, Mijaíl. Problemas literarios y estéticos. Trad. Alfredo Caballero. La

Habana: Arte y Literatura, 1986. Impreso.

Bataille, Georges. La littérature et le mal. Paris: Gallimard, 1957. Impreso. Baudrillard, Jean. Crítica de la economía política del signo. Trad. Aurelio Garzón. México: Siglo XXI, 1982. Impreso.

\footnotetext{
${ }^{32}$ Lo que no ocurre en Sade, por ejemplo, donde la correspondencia entre la forma y el objeto se multiplica hasta la saciedad (Safranski 174-84).
} 
Baudrillard, Jean. La transparencia del mal: Ensayo sobre los fenómenos extremos. Trad. Joaquín Jordá. Barcelona: Anagrama, 1990. Impreso.

Bernal, Rafael. El complot mongol. México: Booket, 2003. Impreso.

Blanco Fernández, Domingo. “¿Un delirio de la virtud? Reflexiones en torno al problema del mal en Kant”. Kant después de Kant: En el bicentenario de la Crítica de la razón práctica. Ed. Javier Muguerza y Roberto Rodríguez Aramayo. Madrid: Tecnos, 1989. 87-116. Impreso.

Bloom, Harold. The Anxiety of Influence: A Theory of Poetry. London y New York: Oxford University Press, 1973. Impreso.

Bolaño, Roberto. Los detectives salvajes. Barcelona: Anagrama, 1998. Impreso.

Bouché, Claude. Lautréamont: Du lieu commun a la parodie. Paris: Larousse, 1974. Impreso.

Campesino, Juan. Estética de la ironía: El signo irónico y su expresión. Madrid: Editorial Académica Española, 2016. Impreso.

Campesino, Juan. "La parodia en el tiempo". Analecta Malacitana 39 (20162017): 247-76. Impreso.

Castilla del Pino, Carlos. Cordura y locura en Cervantes. Barcelona: Península, 2005. Impreso.

Chandler, Raymond. "El simple arte de matar". Trad. Jaume Prat. Teorías del cuento, vol. 2. Ed. Lauro Zavala. México: Universidad Nacional Autónoma de México, 1995. 363-86. Impreso.

Christie, Agatha. El hombre del traje color castaño. Trad. Guillermo López Hipkiss. Barcelona: Molino, 1975. Impreso.

Colvert, James. "El intelectualismo ético de Sócrates". Anuario Filosófico 6.1 (1973): 9-28. Impreso.

Conan Doyle, Arthur. Sherlock Holmes, 2 vols. Trad. Amando Lázaro Ros. México: Aguilar, 1980. Impreso.

Curtius, Ernst. Literatura europea y edad media latina, 2 vols. Trad. Margit Frenk y Antonio Alatorre. México: Fondo de Cultura Económica, 1955. Impreso.

Delepierre, Octave. Essai sur la parodie chez les Grecs, chez les Romains et chez les modernes. London: Trübner, 1870. Digital.

Derrida, Jacques. De la gramatología. Trad. Óscar del Barco y Conrado Ceretti. México: Siglo XXI, 1998. Impreso.

Derrida, Jacques. La diseminación. Trad. José Martín Arancibia. Madrid: Fundamentos, 1975. Impreso.

D'Israeli' Isaac. Curiosities of Literature, vol. 2. London: Routledge, 1858. Impreso.

Du Marsais (César Chesneau).Des tropes. Paris: David, 1757. Impreso.

Eliade, Mircea y Ioan Couliano. Diccionario de las religiones. Trad. Isidro 
Arias. Barcelona: Paidós, 1992. Impreso.

Erikson, Erik. Sociedad y adolescencia. Trad. Andrés Martínez. México: Siglo XXI, 1984. Impreso.

Frazer, George. La rama dorada: Magia y religión. Trad. Elizabeth y Tadeo Campuzano. México: Fondo de Cultura Económica, 1951. Impreso.

Freud, Sigmund. Obras completas, vols. 1 y 7 . Trad. Luis López-Ballesteros. Madrid: Biblioteca Nueva, 1948. Impreso.

Genette, Gerard. Palimpsestos: La literatura en segundo grado. Trad. Celia Fernández. Madrid: Taurus, 1989. Impreso.

Giardinelli, Mempo. El género negro, vol 1. México: Universidad Autónoma Metropolitana, 1984. Impreso.

Gilmont, Jean-Francois. "Reformas protestantes y lectura". Trad. María Barberán. Historia de la lectura en el mundo occidental. Ed. Gugliemo Cavallo y Roger Chartier. México: Taurus, 2006. 329-65. Impreso.

Girard, René. El chivo espiatorio. Trad. Joaquín Jordá. Barcelona: Anagrama, 1986. Impreso.

Girard, René. Mentira romántica y verdad novelesca. Trad. Joaquín Jordá. Barcelona: Anagrama, 1985. Impreso.

Girard, René. La violencia y lo sagrado. Trad. Joaquín Jordá. Barcelona: Anagrama, 1983. Impreso.

González, Aníbal. Abusos y admoniciones. México: Siglo XXI, 2001. Impreso. Green, Dennis. Irony in the Medieval Romance. New York: Cambridge University Press, 1979. Impreso.

Hobbes, Thomas. Leviathan. New York: Dover, 2012. Impreso.

Hutcheon, Linda. A Theory of Parody: The Teachings of Twentieth-Century Art Forms. Urbana and Chicago: University of Illinois Press, 2000. Impreso.

Hutcheon, Linda. "Ironie, satire, parodie: Une approache pragmatique de l'ironie". Poétique 46 (1981): 141-55.

Jenofonte. Recuerdos de Sócrates; Banquete; Apología de Sócrates. Trad. Juan Zaragoza. Madrid: Gredos, 1993. Impreso.

Kant, Immanuel. Lecciones de ética. Trad. Roberto Rodríguez y Concha Roldán. Barcelona: Crítica, 2002. Impreso.

Kierkegaard, Soren. Tratado de la desesperación. Trad. Carlos Liacho. México: Tomo, 2002. Impreso.

Kiremidjian, David. "The Aesthetics of Parody". Journal of Aesthetics and Art Criticism 28 (1969): 231-42. Impreso.

Knox, Ronald. "Un decálogo para el cuento policíaco". Teorías del cuento, vol.

2. Ed. y Trad. Lauro Zavala. México: Universidad Nacional Autónoma de México, 1995. 337-41. Impreso.

Kristeva, Julia. "Bajtín, la palabra, el diálogo y la novela". Intertextualité: Francia en el origen de un término y el desarrollo de un concepto. Comp. y 
Trad. Desiderio Navarro. La Havana: UNEAC/Casa de las Américas, 1997. 1-24. Impreso.

Leibniz, Gottfried. Teodicy: Essays on the Goodness of God, the Freedom of Man and the Origin of Evil. Ed. Austin Farrer. New York: Cosimo, 2010. Impreso.

Lotman, Yuri. Estructura del texto artístico. Trad. Victoriano Imbert. Madrid: Istmo, 1988. Impreso.

Lyotard, Jean-François. El entusiasmo: Crítica kantiana de la historia. Trad.

Alberto Bixio. Barcelona: Gedisa, 1987. Impreso.

Maeztu, Ramiro de. Don Quijote, don Juan y la Celestina. Buenos Aires: Espasa-Calpe, 1938. Impreso.

Malmgreen, Carl. Anatomy of Murder: Mystery, Detective, and Crime Fiction.

Wisconsin: University of Wisconsin Press, 2001. Impreso.

Marmontel, Antoine François. Eléments de littérature, vol. 3. Paris: Verdière, 1825. Impreso.

Marsh, James. "The Irony and Ambiguity of Freedom". Poetics Today 4.3 (1983): 479-92. Impreso.

Martínez Rivas, Carlos. "Memoria para el año Viento inconstante". Prístina y última piedra: Antología de poesía hispanoamericana presente. Ed. Eduardo Milán y Ernesto Lumbreras. México: Aldus, 1999. 3-7. Impreso.

Nash, Walter. The Language of Humor: Style and Technique in Comic Discourse. London: Longman, 1985. Impreso.

Pascual Buxó, José. “Texto y discurso: semiótica e ideología”. Discurso 1 (1984): 45-61. Impreso.

Phiddian, Robert. Swift's Parody. Cambridge: Cambridge Univerity Press, 1995. Impreso.

Piglia, Ricardo. "Lo negro del policíaco". Teorías del cuento, vol. 2. Ed. y Trad. Lauro Zavala. México: Universidad Nacional Autónoma de México, 1995. 399-407. Impreso.

Plantinga, Alvin. "God, Evil, and the Methapysics of Freedom". The Problem of Evil. Ed. Marilyn McCord y Robert Merrihew. New York: Oxford University Press, 1990. 83-109. Impreso.

Platón. Diálogos, vols. 1 y 2. Trad. Julio Calonge, F. J. Olivieri y Carlos García Gual. Madrid: Gredos, 1981 y 1983. Impreso.

Platón. La república. Trad. José Manuel Pavón y Manuel Fernández Galiano. Madrid: Alianza, 1988. Impreso.

Reyes, Alfonso. Obras completas, vol. 4. México: Fondo de Cultura Económica, 1956. Impreso.

Ricoeur, Paul. Finitud y culpabilidad. Trad. Alfonso García y Luis Valdés. Madrid: Taurus, 1991. Impreso.

Ricoeur, Paul. El mal: Un desafio a la filosofía y a la teología. Trad. Irene 
Agoff. Buenos Aires: Amorrortu, 2006. Impreso.

Robertson, William. Thesaurus graecae linguae. London: Johannes Hayes, 1676. Impreso.

Rose, Margaret. Parody: Ancient, Modern, and Post-Modern. Cambridge: Cambridge University Press, 1993. Impreso.

Rosenfield, Denis. Del mal. Trad. Hugo Martínez. México: Fondo de Cultura Económica, 1993. Impreso.

Sade, Donatien Alphonse François de (Marqués). Filosofía en el tocador. Trad. Rubén Ríos. Buenos Aires: Lea, 2006. Impreso.

Safranski, Rüdiger. El mal o el drama de la libertad. Trad. Raúl Gabás. Barcelona: Tusquets, 2000. Impreso.

Sangsue, Daniel. La parodie. Paris: Hachette, 1994. Impreso.

Schopenhauer, Arthur. Los dos problemas fundamentales de la ética. Trad. Pilar López. Madrid: Siglo XXI, 1993. Impreso.

Starobinski, Jean. Las palabras bajo las palabras: La teoría de los anagramas de Ferdinand de Saussure. Trad. Lía Varela y Patricia Willson. Barcelona: Gedisa, 1996. Impreso.

Svenbro, Jesper. "La Grecia arcaica y clásica”. Trad. María Barberán. Historia de la lectura en el mundo occidental. Ed. Gugliemo Cavallo y Roger Chartier. México: Taurus, 2006. 57-93. Impreso.

Tinianov, Yuri. "Sobre la evolución literaria". Trad. Ana María Nethol. Teoría de la literatura de los formalistas rusos. Ed. Tzvetan Todorov. México: Siglo XXI, 2007. 89-99. Impreso.

Tomás de Aquino (santo). On Evil. Trad. Richard Regan. New York: Oxford University Press, 2003. Impreso.

Trías, Eugenio. Lo bello y lo siniestro. Barcelona: Debolsillo, 2006. Impreso. Urbina, Eduardo. "Ironía medieval, parodia renacentista y la interpretación del Quijote". Actas del VIII Congreso de la Asociación Internacional de Hispanistas, vol. 2. España: Ediciones Istmo, 1983. 669-80. Impreso.

Van Dine, S. S. "Las convenciones del relato policíaco". Trad. F. le Lionnais. Teorías del cuento, vol. 2. Ed. Lauro Zavala. México: Universidad Nacional Autónoma de México, 1995. 331-35. Impreso.

Wolf, Maryanne. Cómo aprendemos a leer. Trad. Martín Rodríguez-Courel. Barcelona: Ediciones B, 2008. Impreso.

Zohar. Libro del esplendor. Trad. Esther Cohen y Ana Castaño. México: Conaculta, 2010. Impreso.

Zubiri, Xavier. Sobre el sentimiento y la volición. Madrid: Alianza, 1993. Impreso. 